\title{
Fabrication and Characterization of Self- microemulsifying Mouth Dissolving Film for Effective Delivery of Piroxicam
}

\author{
SEEMA PATTEWAR*, V. PANDE ${ }^{1}$, D. PATIL ${ }^{2}$ AND S. SHARMA \\ Department of Pharmacy, Banasthali Vidyapith, Banasthali, Rajasthan-304 022, ${ }^{1}$ Sanjivani College of Pharmaceutical \\ Education and Research, ${ }^{2}$ Sanjivani Institute of Pharmacy and Research, Kopargaon-423 603, India
}

\author{
Pattewar et al.: Self-microemulsifying Mouth Dissolving Film
}

\begin{abstract}
Self-microemulsifying drug delivery systems are widely used to address water-solubility issues of drug candidates, but with these systems, there is a chance of drug precipitation due to migration of the surfactant in the shell of capsule. Piroxicam is a class II drug that exhibits poor solubility and high permeability. Efforts were made to develop piroxicam self-microemusifying mouth dissolving film using a polymer such as hydroxylpropyl methylcellulose as a film-forming polymer and optimized using response surface methodology of Design-Expert ${ }^{\circledR}$ software version 10. A sublingual self-microemusifying mouth dissolving film was prepared that disintegrated in 26 seconds. The in vitro drug release of self-microemusifying mouth dissolving film was $\mathbf{9 8 . 0 4} \pm \mathbf{0 . 0 1 6} \%$ in 5 min. The newly developed sublingual self-microemusifying mouth dissolving film provided rapid absorption of piroxicam $\left(\mathrm{t}_{\max } \sim 2 \mathrm{~h}\right)$ and suitable for providing a rapid onset of analgesic action.
\end{abstract}

Key words: Mouth dissolving film, piroxicam, response surface methodology, self-microemulsifying drug delivery system, self-microemulsifying mouth dissolving film

Various routes of drug administration are available with their own significances, merits and demerits ${ }^{[1]}$. Parenteral, transdermal and submucosal routes of drug administration requires medical expertise and is painful for the patient. On contrary oral route avoids such pain or medical assistance and is more patient friendly, economic and with good therapeutic efficacy ${ }^{[2,3]}$.

Low solubility and ultimately low bioavailability of drugs is a challenge faced by the pharmaceutical industry. Self-emulsifying drug delivery systems (SEDDS) form a fine microemulsion when diluted with an aqueous phase. The dissolution as well as the stability of a drug are generally enhanced in SEDDS ${ }^{[4]}$. Selfmicroemulsifying drug delivery systems (SMEDDS) are isotropic mixtures of oils, surfactants and cosurfactants with droplet size smaller than SEDDS. SMEDDS are used to improve the oral bioavailability of hydrophobic drugs. The bioavailability of a drug is increased when Labrafil (a bioavailability enhancer and solubilizer for poorly water-soluble compounds) is used with a surfactant propylene glycol and a cosurfactant Cremophor RH40 ${ }^{[5,6]}$. The droplet size of a SMEDDS increases as the quantity of oil in the formulation increases ${ }^{[7]}$. SMEDDS improves the oral absorption of a lipophilic drug. The absorption of a drug after it is administered orally using SMEDDS depended on the surfactant concentration, oil/surfactant ratio, charge and droplet size ${ }^{[8]}$. With the help of pseudo-ternary phase diagrams one can evaluate the microemulsification area, which helps formulation of SMEDDS ${ }^{[9]}$. Solid SMEDDS can be prepared by filling hard gelatin capsules with liquid SMEDDS. Solid SMEDDS overcome the disadvantages of liquid formulations ${ }^{[2]}$, but a drug may get precipitated in such systems. The surfactant may migrate into the gelatin shell, resulting in drug precipitation. Mouth dissolving films (MDFs) are a convenient dosage form, dissolves within minutes in the oral cavity, without chewing and can improve the onset of drug action and enhance the efficacy of a drug ${ }^{[10]}$. The purpose of this study

This is an open access article distributed under the terms of the Creative Commons Attribution-NonCommercial-ShareAlike 3.0 License, which allows others to remix, tweak, and build upon the work non-commercially, as long as the author is credited and the new creations are licensed under the identical terms

Accepted 15 April 2019

Revised 25 December 2018

Received 01 September 2018

Indian J Pharm Sci 2019;81(3):503-513 
was to develop a novel self-microemulsifying mouth dissolving film (SMMDF) based on a MDF integrated with self-microemulsifying components.

The advantages of SMMDF are that it releases the drug quickly and has great potential for enhancing oral dissolution and bioavailability of poorly water soluble drug; it does not require water during administration; taste masking is possible; no risk of chocking; offers good patient compliance; it has flexible and portable nature so ease in handling and avoids first past metabolism. However, there are some disadvantages with SMMDF, which are, only low dose drug can be incorporated (less than $30 \mathrm{mg}$ ), dose uniformity is a challenge; it takes moisture from atmosphere so it requires special packaging for product's stability and safety.

\section{MATERIALS AND METHODS}

Piroxicam was obtained as a gift sample from Apex Healthcare Limited, Gujarat, India. Capmul medium chain mono diglyceride (MCM), citric acid, aspartame and Polystardone XL crospovidone were obtained as gift samples from Intas Pharmaceuticals Ltd., Ahmedabad, India. Cremophor-EL (macrogolglycerol ricinoleate), Transcutol P(diethylene glycol monoethyl ether), hydroxypropyl methylcellulose (HPMC) E15, low-substituted hydroxypropyl cellulose (L-HPC) and polyethylene glycol 400 were obtained as gift samples from Dr. Reddy's Laboratories Ltd., Hyderabad, India. Neusilin US2 (magnesium aluminometasilicate) was obtained as a gift sample from Gangwal Chemicals Pvt. Ltd., Mumbai, India.

\section{Formulation of liquid SMEDDS (L-SMEDDS):}

A study on solubility of piroxicam in oils (Capmul MCM), surfactants (Cremophor EL) and co-surfactants (Transcutol P) was carried out ${ }^{[11-13]}$. Piroxicam was more soluble in Capmul MCM (7.1372 $\mathrm{mg} / \mathrm{ml})$, Cremophor EL (11.94 mg/ml) and Transcutol P $(11.81 \mathrm{mg} / \mathrm{ml})$. Different SMEDDS were formulated using the phase diagrams created by CHEMIX School software package ${ }^{[14]}$. Piroxicam $(10 \mathrm{mg})$ was transferred into a screw-capped glass vial containing the selected oil and a mixture of the surfactant and cosurfactant (Smix in 2:1 ratio) and stirred using a vortex mixer to obtain a homogenous solution. The SMEDDS prepared thus was stored at room temperature in sealed transparent vials until use ${ }^{[15-18]}$.

\section{Experimental design for SMEDDS:}

Optimization of the piroxicam SMEDDS was achieved using 2 level factorial designs. From the preliminary study, oil, surfactant and co-surfactant were selected for L-SMEDDS formulation. Quantities of Capmul MCM, Cremophor EL were selected as the two factors for optimization. Two levels for each factor were used to construct experimental design. Levels for Capmul MCM (25.88, $30.88 \%)$ and Cremophor EL (38.82, $52.23 \%$ ) were selected from the preliminary study. Drug content and $\%$ transmittance was selected as response for optimization. Four experiments were planned as per $2^{2}$ factorial designs. Response surface diagram was constructed and those transparent formulations exhibiting no precipitation were studied further. The formulation was optimized using a response surface diagram produced using Design-Expert ${ }^{\circledR}$ software version 10 (Stat-Ease) ${ }^{[19]}$.

\section{Fourier-transform infrared spectroscopy (FTIR) study:}

FTIR is a useful technique to analyse chemical reactions between excipients and drugs. The FTIR spectra of the drug, the SMEDDS with the drug, a physical mixture of the SMMDF and all the excipients were recorded using FTIR spectrophotometer (Shimadzu 4800, Japan). The samples were scanned for absorbance over the range from 4000 to $400 \mathrm{~cm}^{-1}$ at a resolution of $1 \mathrm{~cm}^{-1}$. The spectra obtained were compared with the standard group frequencies of piroxicam.

\section{Preparation of SMMDF formulations using the solvent casting method:}

HPMC has good film-forming properties. Different HPMC grades, such as Methocel E3, Methocel E5, Methocel E6 and Methocel E15 Premium LV, were evaluated for the use as primary film former. Initially, placebo SMMDFs were prepared with the various grades of HPMC and PEG 400. HPMC E15 was selected for further development with PEG 400 as a plasticizer. HPMC E15 was selected on the basis of its film-forming property and inertness. Aspartame was used as a sweetening agent to mask the bitter taste of piroxicam. Citric acid was used as a saliva-stimulating agent, and the novel Polystardone XL crospovidone was used as a disintegrating agent. Neusilin US2 was used to adsorb the self-microemulsifying components. L-HPC was used to serve as a disintegrating agent and film former ${ }^{[2]}$. 
TABLE 1: TRIAL BATCH OF SMMDF USING HPMC E15 AND PEG 400

\begin{tabular}{lccccc}
\hline Components (g) & Q1 & Q2 & Q3 & Q4 & Q5 \\
\hline Piroxicam & 0.189 & 0.189 & 0.189 & 0.189 & 0.189 \\
HPMC E15 & 0.250 & 0.300 & 0.350 & 0.400 & 0.450 \\
L-HPC & 0.018 & 0.018 & 0.018 & 0.018 & 0.018 \\
Neusilin US2 & 0.162 & 0.162 & 0.162 & 0.162 & 0.162 \\
PEG400 & 0.05 & 0.05 & 0.05 & 0.05 & 0.05 \\
Citic acid & 0.032 & 0.032 & 0.032 & 0.032 & 0.032 \\
Aspartame & 0.032 & 0.032 & 0.032 & 0.032 & 0.032 \\
Polystardone XL & 0.032 & 0.032 & 0.032 & 0.032 & 0.032 \\
crospovidone & 0.28 & 0.28 & 0.28 & 0.28 & 0.28 \\
Capmul MCM & 0.44 & 0.44 & 0.44 & 0.44 & 0.44 \\
Cremophore EL & 0.28 & 0.28 & 0.28 & 0.28 & 0.28 \\
Transcutol P & 15 & 15 & 15 & 15 & 15 \\
Distilled water (ml) & \multicolumn{5}{c}{ 15 } \\
SMMDF is self-microemulsifying mouth dissolving film
\end{tabular}

Formulation of SMMDF:

On the basis of previous research ${ }^{[20]}$, the SMMDF was formulated using the solvent casting method (Table 1$)^{[21,22]}$. Half the quantity of piroxicam was dissolved in a SMEDDS composed of Capmul MCM, Cremophor EL and Transcutol P. The rest of piroxicam was co-ground with HPMC E15. The other excipients of the formulation, like L-HPC, Neusilin US2, PEG 400, citric acid, aspartame and Polystardone XL crospovidone, were dispersed or dissolved in the appropriate quantity of water. The mixture was stirred using a magnetic stirrer (Remi Instruments) for $1 \mathrm{~h}$ and made to stand for $1 \mathrm{~h}$ to remove entrapped air bubbles. The mixture was transferred to a petri dish and dried at room temperature until it became easy to peel out from petri dish. The resultant dry film was peeled from the petri dish and checked for imperfections. The SMMDF was cut into $2 \times 2 \mathrm{~cm}$ squares, in which $10 \mathrm{mg}$ piroxicam was included. The film was packed in butter paper and then covered in an aluminium foil. The film was then stored in an airtight container. The area and the total amount of drug were calculated for each batch.

\section{Optimization of SMMDF:}

The effect of two factors on the mechanical property of SMMDF was studied at 3 levels. HPMC E15 $\left(\mathrm{X}_{1}\right)$ and PEG $400\left(\mathrm{X}_{2}\right)$ concentrations were selected as the independent variables. The in vitro disintegration time, percent drug release and tensile strength were selected as the dependent variables. The values of the variables in the $3^{2}$ full factorial designs are provided in Table 2.

\section{Evaluation of SMMDF:}

Properties of the sublingual SMMDF such as the colour and surface texture were evaluated by visual inspection, and the texture was evaluated by touching them. The SMMDF films were weighed and the average weight of the film was determined. The SMMDF was wetted with distilled water and the $\mathrm{pH}$ determined by placing an electrode on the surface of the film. Drug content was quantified by dissolving the SMMDF containing the drug in $50 \mathrm{ml}$ of $0.1 \mathrm{M} \mathrm{HCl}$ in methanol. The mixture was shaken well and an aliquot of $1 \mathrm{ml}$ was diluted to $10 \mathrm{ml}$ with $0.1 \mathrm{M} \mathrm{HCl}$ in methanol. The solution was filtered and analysed using a UV spectrophotometer at $334 \mathrm{~nm}$. Folding endurance was calculated by folding SMMDF a number of times at the same place without break. Thickness was determined using a Mitutoyo digital thickness gauge ${ }^{[23]}$. Disintegration time was determined at $37^{\circ}$ in a disintegration test apparatus using $2 \times 2 \mathrm{~cm}$ samples. Time required for the SMMDF to break was noted as in vitro disintegration time. The test was performed on three SMMDF of each formulation batch and mean $\pm \mathrm{SD}$ was calculated ${ }^{[24,25]}$.

An in vitro dissolution study of the SMMDF was carried out at $37 \pm 0.5^{\circ}$ in $900 \mathrm{ml}$ of $\mathrm{pH} 6.8$ phosphate buffer using a USP dissolution apparatus type-II (paddle type) at $50 \mathrm{rpm}$. SMMDF samples of size $2 \times 2 \mathrm{~cm}$ (containing $10 \mathrm{mg}$ of piroxicam) were subjected to an in vitro dissolution study. At predetermined time intervals $5 \mathrm{ml}$ aliquots were removed $(30,60,90,120$, $150,180,210,240,270$ and $300 \mathrm{~s})$ from the dissolution medium, each time replacing with $5 \mathrm{ml}$ of fresh $\mathrm{pH} 6.8$ phosphate buffer. The samples were analysed using a UV spectrophotometer at $355 \mathrm{~nm}^{[26]}$.

Texture profile analysis ${ }^{[25,27]}$ was carried out to determine the tensile strength, percent elongation at break $(\% \mathrm{E})$, Young's modulus $(\mathrm{E})^{[28,29]}$ and tear resistance. Tensile strength was determined using texture profile analyser (Texture Pro CT V 1.8 Build 29 machine by Brookfield Engineering). Before loading the SMMDF in machine, the computer system connected to the machine was set up by inputting the necessary information of gauge length and width of the film. The computer system was then prepared to record data. Testing involves applying an ever-increasing load to a test sample up to the point of failure. Tensile strength is the maximum stress applied to a point at

TABLE 2: FORMULATION FACTORS CONCENTRATION AND LEVELS

\begin{tabular}{lcccccc}
\hline Factors & HPMC E15 $\left(\mathrm{X}_{1}\right)$ & \multicolumn{4}{c}{$\begin{array}{c}\text { Polyethylene } \\
\text { glycol } 400\end{array}$} \\
\hline Concentration $(\mathrm{g})$ & 0.225 & 0.325 & 0.425 & 0.03 & 0.04 & 0.05 \\
Levels & -1 & 0 & +1 & -1 & 0 & +1 \\
\hline
\end{tabular}


which the film breaks. It was calculated by the applied load at rupture divided by the cross-sectional area (film thickness $\times$ film width). It was calculated in $\mathrm{kg} / \mathrm{mm}^{2}$. Percent elongation at break ( $\%$ E) was obtained by dividing the extension at the moment of rupture of film by the initial length of film and multiplying it by 100 . Young's modulus (E) can be defined as ratio of stress to strain. Typical value for Young's modulus of a film was $0.30 \pm 0.07 \mathrm{MPa}$. Tear resistance is the maximum stress or force to tear the SMMDF. It was calculated in Newton.

\section{Differential scanning calorimetry (DSC):}

Thermal analysis was performed using a DSC (MettlerToledo, Greifensee, Switzerland). The sample (2 mg) was analysed in a sealed and pin-holed standard $40 \mu \mathrm{l}$ aluminium pan, with a heating rate of $10^{\circ} / \mathrm{min}$ from $40^{\circ}$ to $260^{\circ}$ and during the measurement, the sample cell was continuously purged with nitrogen at a flow rate of $40 \mathrm{ml} / \mathrm{min}$. The instrument was calibrated with indium. DSC thermograms were recorded for samples.

\section{$\mathrm{X}$-ray powder diffractometry:}

The physical state of the piroxicam in the SMMDF was evaluated using a powder X-ray diffractometer (Bruker Model D8 Advance, Germany). The instrument was set with B-B geometry. The current and voltage was set to $40 \mathrm{mV}$ and $35 \mathrm{~mA}$, respectively and data was collected $^{[2]}$.

\section{Morphological study of SMMDF:}

A morphological study was conducted to evaluate the distribution of API in the SMMDF. The SMMDF was cut into pieces of size $2 \times 2 \mathrm{~cm}$ and one piece was mounted on a metal stub with adhesive tapes. The outer macroscopic surface characteristics of the SMMDF were studied using a scanning electron microscope (Jeol, JSM 6390LA, Japan) $)^{[2]}$.

\section{Stability studies:}

Out of nine batches of SMMDF films, the optimized batch was subjected to stability studies according to ICH Q1A $\left(\mathrm{R}_{2}\right)$ guidelines. The films were stored in aluminium foil at $30 \pm 2^{\circ}$ and $75 \pm 5 \% \mathrm{RH}$ for $12 \mathrm{mo}$ for long-term testing in stability chamber (CHM-10S Remi, India).

\section{Determination of pharmacokinetic parameters in rabbits:}

New Zealand albino rabbits (weighing around $2.0 \mathrm{~kg}$ ) of either sex were used for the present study. In house bred rabbits acquired from the Columbia Institute of Pharmacy, Raipur were used for the present study. Experimental protocol used was approval by the Institutional Animal Ethics Committee of the Columbia Institute of Pharmacy, Raipur with reference 1321/PO/ $\mathrm{ReBi} / \mathrm{S} / 10 / \mathrm{CPCSEA}$ dated 22/10/2014.

Rabbits of equal weight were divided in 2 groups; first group was considered as the test group and was treated with piroxicam SMMDF (10 mg) via sublingual route whereas rabbits of the second group were titled as standard and treated with piroxicam marketed tablet $(10 \mathrm{mg})$ orally. For sublingual administration of patch (SMMDF), the rabbit's mouth was opened, the tongue was elevated by forceps and SMMDF was placed below tongue by another forceps. Mouth was closed for 5 min to avoid chewing or swallowing of SMMDF whereas for the second group marketed piroxicam tablet $(10 \mathrm{mg})$ was administered with an oropharyngeal cannula $^{[30]}$.

\section{Blood sample collection and processing:}

Blood was withdrawn from marginal ear vein of rabbit at $0,0.5,1,2,4,6,8,16,24 \mathrm{~h}$ after administration. The blood samples were collected in lithium heparin containing tubes and centrifuged at $12000 \mathrm{rpm}$ for $10 \mathrm{~min}$. The plasma was removed and processed for extraction. Calibration curve of piroxicam were prepared by dilution of piroxicam stock solution $(1 \mathrm{mg} / \mathrm{ml}$ in $\mathrm{pH} 8.0$ phosphate buffer $0.04 \mathrm{M})$. Then $0.1 \mathrm{ml}$ plasma sample was transferred in $20 \times 150 \mathrm{~mm}$ glass tubes with caps. To this, $50 \mu 1$ of internal standard (piroxicam, $0.1 \mathrm{mg}$ per $\mathrm{ml}$ in $\mathrm{pH} 8.0$ phosphate buffer $0.04 \mathrm{M}), 0.2 \mathrm{ml}$ of $\mathrm{pH} 2.0$ phosphate buffer $(1.0 \mathrm{M})$ and methylene chloride $(5 \mathrm{ml})$ were added. The tubes were shaked for $10 \mathrm{~min}$. and centrifuged at $12000 \mathrm{rpm}$ for $10 \mathrm{~min}$. Aqueous layer was removed and organic layer was dried under nitrogen. The samples so obtained were diluted with $0.1 \mathrm{ml}$ of mobile phase. Separation was done by chromatography on a $\mathrm{C} 18$ column. Mobile phase selected and optimized was $45 \%$ methanol in $\mathrm{pH} 8.0$ phosphate buffer and the flow rate was adjusted as $1.0 \mathrm{ml} / \mathrm{min}$. Detector UV was set at $330 \mathrm{~nm} .20 \mu \mathrm{l}$ of the diluted solution was injected onto the HPLC column $^{[30]}$.

After measuring piroxicam concentrations in plasma, various pharmacokinetics parameters were also assessed such as the maximum concentration $\left(\mathrm{C}_{\max }\right)$, time taken to reach $\mathrm{C}_{\max }\left(\mathrm{t}_{\max }\right)$, area under the curve 


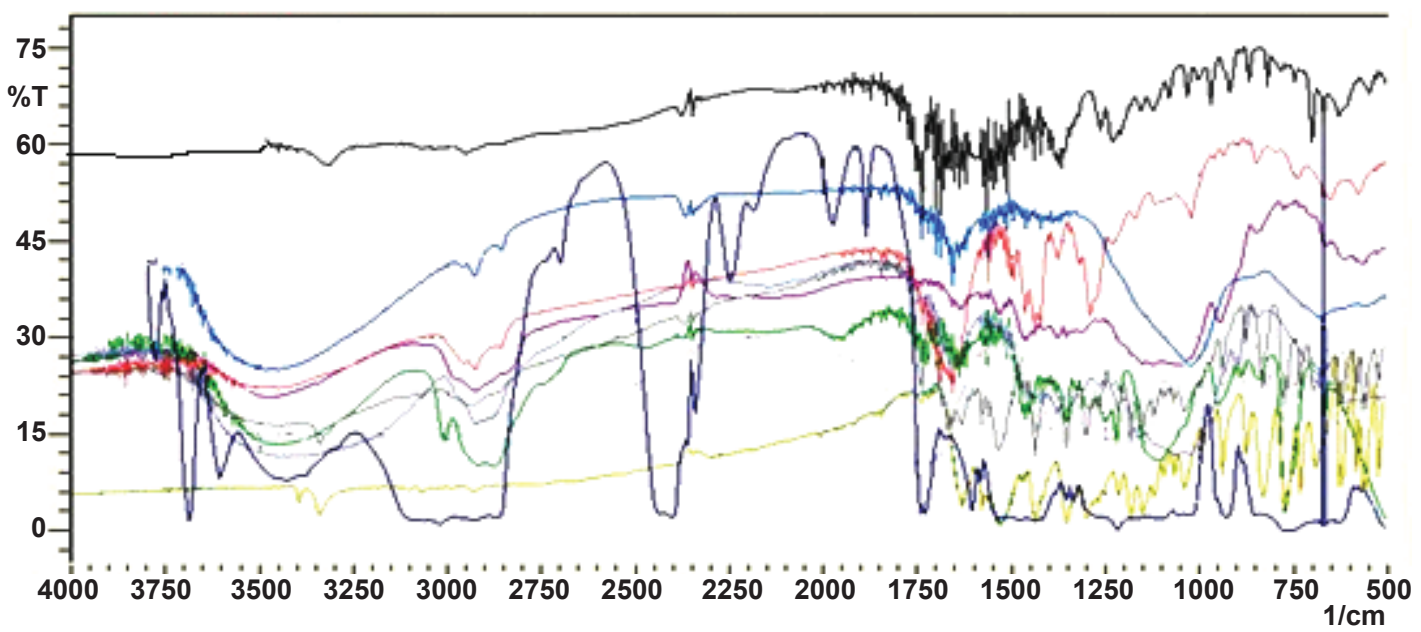

Fig. 1: FTIR spectra

$(-)$ HPMC E 15; (-) PEG 400; (-) drug piroxicam; (-) aspartame; (-) citric acid; (-) SMEDDS with drug; (-) Neusilin US 2; (-) physical mixture of formulation; $(-)$ Polystardone XL crospovidone; $(-)$ LHPC

(AUC), volume of distribution $\left(\mathrm{V}_{\mathrm{d}}\right)$, elimination halflife $\left(\mathrm{t} \frac{1}{2}\right)$ and compared these parameters with marketed formulation of dispersible tablet ${ }^{[31]}$.

\section{RESULTS AND DISCUSSION}

The FTIR spectra of piroxicam, SMEDDS with the drug, all excipients and a physical mixture of the formulation are shown in fig. 1. The FTIR spectrum of piroxicam shows that functional group frequencies of piroxicam are in the reported range, which indicates the purity of the piroxicam. It has been reported that piroxicam has two inter-convertible crystalline forms, namely the needle and cubic forms. The peak in the spectrum at $3338 \mathrm{~cm}^{-1}$ assigned to $\mathrm{N}-\mathrm{H}$ stretching and that at $1629.90 \mathrm{~cm}^{-1}$ assigned to the stretching of the amide carbonyl, suggesting that the cubic form of piroxicam was used ${ }^{[32]}$. The piroxicam spectrum shows a peak at $3450 \mathrm{~cm}^{-1}$ that assigned to $\mathrm{O}-\mathrm{H}$ stretching and one at $1180.47 \mathrm{~cm}^{-1}$ assigned to asymmetric stretching of $\mathrm{S}=\mathrm{O}$. The SMEDDS formulation shows a peak at $1728.28 \mathrm{~cm}^{-1}$ assigned to $\mathrm{C}=\mathrm{O}$ amide carbonyl, one at $3442.09 \mathrm{~cm}^{-1}$ assigned to $\mathrm{N}-\mathrm{H}$ stretching, one at $3604.11 \mathrm{~cm}^{-1}$ assigned to $\mathrm{O}-\mathrm{H}$ stretching and one at $1217.12 \mathrm{~cm}^{-1}$ assigned to asymmetric stretching of $\mathrm{S}=\mathrm{O}$. The physical mixture of the SMMDF shows a peak at $1734.06 \mathrm{~cm}^{-1}$ assigned to amide carbonyl $\mathrm{C}=\mathrm{O}$, one at $3337.93 \mathrm{~cm}^{-1}$ assigned to secondary $\mathrm{N}-\mathrm{H}$ stretching, $3628.22 \mathrm{~cm}^{-1}$ assigned to $\mathrm{O}-\mathrm{H}$ stretching and one at $1299.10 \mathrm{~cm}^{-1}$ assigned to asymmetric stretching of $\mathrm{S}=\mathrm{O}$.

The $\mathrm{N}-\mathrm{H}$ group of the amide in piroxicam formed a hydrogen bond with the carboxyl group of an excipient of the SMEDDS (dilute form of piroxicam), and this reduced the electron density on the nitrogen. This led to shifting of the $\mathrm{C}=\mathrm{O}$ stretch of the amide carbonyl. In SMEDDS and SMMDF, piroxicam was present in a solubilized form or diluted form ${ }^{[33]}$. The IR spectra of the physical mixture of the SMMDF formulation indicated that there were no remarkable changes in the location of the characteristic infrared absorption bands of the drug, suggesting that there was no interaction between piroxicam and the excipients.

Optimization of the piroxicam SMEDDS was performed using a two-level factorial design. From the preliminary study, Capmul MCM was selected as the oil, Cremophor EL as the surfactant and Transcutol $\mathrm{P}$ as the co-surfactant. A formulation was prepared that contained $28.26 \%$ Capmul MCM, $44.16 \%$ Cremophore EL and $27.58 \%$ Transcutol P according to the solution provided by Design Expert 10. Due to the presence of liquid ingredients such as the oil, surfactant and co-surfactant in the formulation, a problem was encountered in preparing films. To solve this, an oil-adsorbing agent, namely Neusilin US2 was added. The Neusilin US2 imparted a white colour to the film. The new disintegrating agent Polystardone XL crospovidone helped the film to disintegrate quickly. The solubility of the piroxicam increased after it was co-ground with HPMC E15. The HPMC E15 showed surfactant activity, reduced the contact angle and increased the wetting of the drug particles, thereby enhancing the solubilisation of the drug particles. Synthetic polymers have the potential to enhance solubility upon co-grinding. If the viscosity of the HPMC is high, then these polymers produce a gel layer on the hydrated surfaces, which prevents the drug from 
being released during drug dissolution and reduces the dissolution. Hence it is preferable to use low-viscosity polymer grades such as HPMC E15. Other lowviscosity polymers grades such as HPMC E3, HPMC E5 and HPMC E6 have low viscosities, but their filmforming ability is poor compared with HPMC E15 $5^{[34]}$.

The properties of sublingual SMMDF were evaluated by visual inspection. The surface of the SMMDF was found to be rough and white in colour. The weights of all the films were found to be same. The film had good mechanical strength and flexibility. The results of surface $\mathrm{pH}$, drug content, folding endurance, thickness were showed in Table 3. Each batch contained a different amount of polymer, and the thickness increased gradually with increasing amount of polymer.

The mean disintegration time of the film formulations were found to be in the range of 26-27 s and so they pass the criterion for the disintegration test (5-30 s) of oral films (Table 4) ${ }^{[25,35]}$.

The percent release of the pure drug in $\mathrm{pH} 6.8$ phosphate buffer was only $60 \%$ in $120 \mathrm{~min}^{[36]}$. The in vitro drug release of all the formulations of the orodispersible tablets was found to be in the range 64.5-102.4\% after $45 \mathrm{~min}^{[37]}$. The in vitro dissolution study of the SMMDF of all the batches was performed for $300 \mathrm{~s}$, or $5 \mathrm{~min}$, as shown in fig. 2. All the SMMDF formulations showed rapid dissolution, from $95.65 \pm 0.04$ to $98.04 \pm 0.016 \%$.

The tensile strength of the films was found to be between 0.55 and $1.00 \mathrm{~kg} / \mathrm{mm}^{2}$. The percent elongation

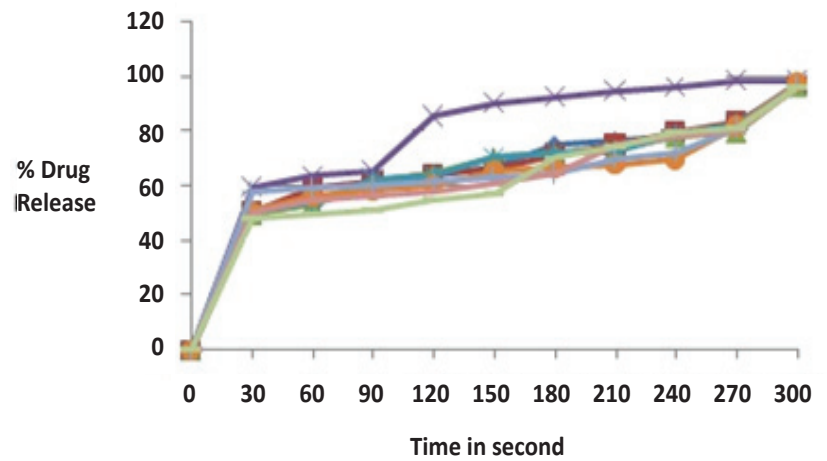

Fig. 2: In vitro dissolution study of self-microemulsifying mouth dissolving films

(-) F1; (-) F2; (-) F3; (-) F4; (-) F5; (-) F6; (-) F7; (-) F8 and $(-)$ F9

TABLE 3: EVALUATION PARAMETERS OF ALL BATCHES

\begin{tabular}{lccccccc}
\hline Batch & $X_{1}$ & $X_{2}$ & Drug content $(\%)$ & $\begin{array}{c}\text { Thickness } \\
(\mathrm{mm})\end{array}$ & Weight variation $(\mathrm{g})$ & $\% \mathrm{E}$ & $\begin{array}{c}\text { Surface pH } \\
\text { endurance } \\
(\mathrm{no} \text { of folds) }\end{array}$ \\
\hline FF1 & 1 & 1 & $98.95 \pm 0.0169$ & $0.025 \pm 0.0008$ & $0.065 \pm 0.0012$ & 11.8 & $6.78 \pm 0.14$ \\
FF2 & -1 & 1 & $99.816 \pm 0.0124$ & $0.026 \pm 0.0000$ & $0.066 \pm 0.0004$ & 5.46 & $6.80 \pm 0.08$ \\
FF3 & 0 & -1 & $100 \pm 0.0000$ & $0.025 \pm 0.0016$ & $0.064 \pm 0.0012$ & 4.76 & $7.12 \pm 0.053$ \\
FF4 & 1 & -1 & $99.87 \pm 0.0169$ & $0.026 \pm 0.0008$ & $0.060 \pm 0.0004$ & 11.5 & $7.00 \pm 0.067$ \\
FF5 & -1 & -1 & $99.754 \pm 0.0081$ & $0.026 \pm 0.0004$ & $0.062 \pm 0.001$ & 12.4 & $6.74 \pm 0.032$ \\
FF6 & 1 & 0 & $99.44 \pm 0.0124$ & $0.026 \pm 0.0016$ & $0.059 \pm 0.001$ & 10.6 & $6.90 \pm 0.009$ \\
FF7 & 0 & 0 & $99.14 \pm 0.0216$ & $0.024 \pm 0.0012$ & $0.058 \pm 0.0004$ & 11.7 & $6.92 \pm 0.008$ \\
FF8 & -1 & 0 & $98.89 \pm 0.0326$ & $0.026 \pm 0.0004$ & $0.065 \pm 0.0004$ & 9.4 & $6.94 \pm 0.122$ \\
FF9 & 0 & 1 & $99.93 \pm 0.0262$ & $0.025 \pm 0.0016$ & $0.063 \pm 0.0008$ & 7.1 & $6.96 \pm 0.016$ \\
\hline
\end{tabular}

Results are expressed as mean $\pm S D(n=3), X_{1}$ is concentration of polymer $(g) ; X_{2}$ is concentration of plasticizer $(g)$ and \% $E$ is percent elongation at break

TABLE 4: FULL FACTORIAL DESIGN EXPERIMENT FOR SMMDF

\begin{tabular}{|c|c|c|c|c|c|c|c|c|c|}
\hline \multirow{3}{*}{ Run } & \multirow{3}{*}{ Batch } & \multirow{2}{*}{\multicolumn{2}{|c|}{ Independent variables }} & \multicolumn{6}{|c|}{ Dependent variables } \\
\hline & & & & \multicolumn{3}{|c|}{ Observed value } & \multicolumn{3}{|c|}{ Predicted value } \\
\hline & & $X_{1}$ & $x_{2}$ & $Y_{1}$ & $Y_{2}$ & $Y_{3}$ & $Y_{1}$ & $Y_{2}$ & $Y_{3}$ \\
\hline 1 & FF1 & 1 & 1 & 27 & 97 & 1 & 27.22 & 96.93 & 1.02 \\
\hline 2 & FF2 & -1 & 1 & 27 & 95.65 & 0.743 & 26.89 & 95.51 & 0.75 \\
\hline 3 & FF3 & 0 & -1 & 26 & 96.31 & 0.68 & 26.06 & 96.99 & 0.69 \\
\hline 4 & FF4 & 1 & -1 & 26 & 98.04 & 0.84 & 26.22 & 97.70 & 0.82 \\
\hline 5 & FF5 & -1 & -1 & 26 & 96.61 & 0.55 & 25.89 & 96.28 & 0.54 \\
\hline 6 & FF6 & 1 & 0 & 27 & 97.48 & 0.92 & 26.72 & 97.32 & 0.92 \\
\hline 7 & FF7 & 0 & 0 & 27 & 96.4 & 0.77 & 26.56 & 96.61 & 0.79 \\
\hline 8 & FF8 & -1 & 0 & 26 & 96 & 0.66 & 26.39 & 95.90 & 0.65 \\
\hline 9 & FF9 & 0 & 1 & 27 & 96 & 0.906 & 27.06 & 96.22 & 0.88 \\
\hline
\end{tabular}

SMMDF is self-microemulsifying mouth dissolving film, $X_{1}$ is the concentration of polymer $(g), X_{2}$ is the concentration of plasticizer ( $g$ ), $Y_{1}$ is disintegration time (s), $Y_{2}$ is drug release $(\%)$ and $Y_{3}$ is tensile strength $\left(\mathrm{kg} / \mathrm{mm}^{2}\right)$ 
at breaking was found between 4.76 and $12.4 \%$ as shown in Table 5. The typical Young's modulus value of a film is $0.30 \pm 0.07 \mathrm{MPa}$. The optimized batch of SMMDF had a Young's modulus value of

\section{TABLE 5: SUMMARY OF THE LINEAR MODEL}

\begin{tabular}{lccccc}
\hline Response & $\mathbf{R}^{2}$ & Adjusted $\mathbf{R}^{2}$ & Predicted $\mathbf{R}^{2}$ & $\mathrm{SD}$ & $\% \mathbf{C V}$ \\
\hline$Y_{1}$ & 0.7500 & 0.6667 & 0.5051 & 0.30 & 1.15 \\
$Y_{2}$ & 0.8233 & 0.7644 & 0.6005 & 0.37 & 0.39 \\
$Y_{3}$ & 0.9906 & 0.9874 & 0.9782 & 0.016 & 2.06 \\
\hline
\end{tabular}

$Y_{1}$ is disintegration time (s), $Y_{2}$ is drug release (\%) and $Y_{3}$ is tensile strength $\left(\mathrm{kg} / \mathrm{mm}^{2}\right)$

A.

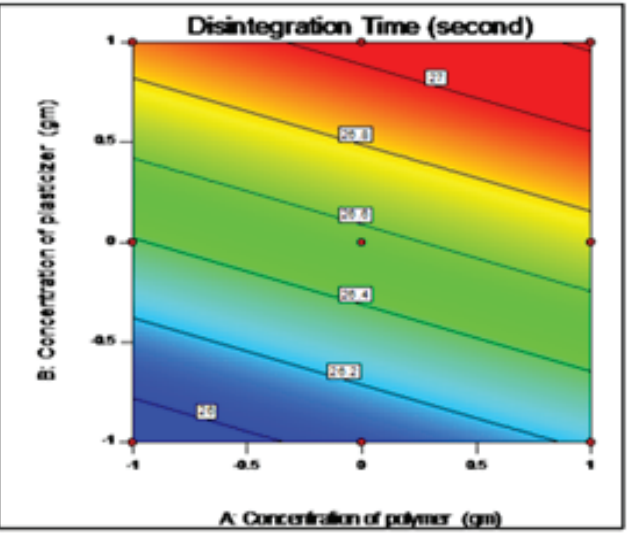

B.

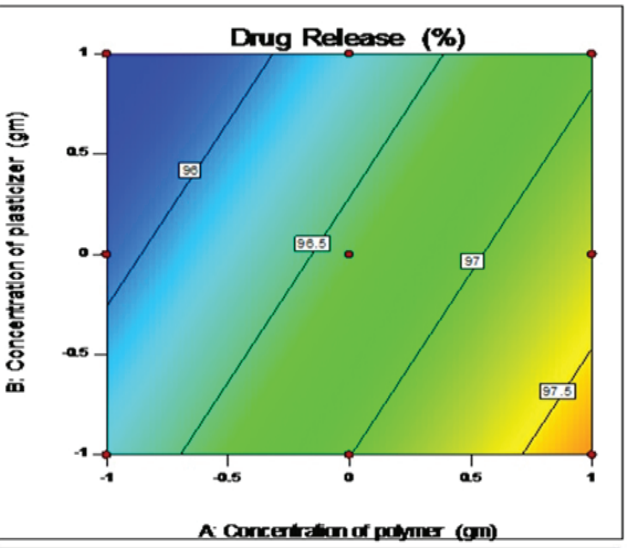

C.

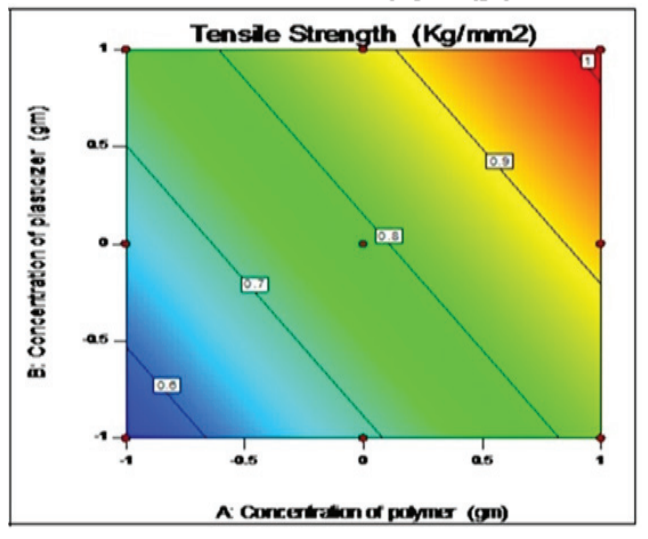

Fig. 3: Effect of polymer and plasticizer concentrations on responses $Y_{1}, Y_{2}$ and $Y_{3}$

Contour plots showing the effect of polymer concentration $\left(X_{1}\right)$ and plasticizer concentration $\left(X_{2}\right)$ on responses, $A . Y_{1}$, the disintegration time (s), B. $Y_{2}$, the drug release $(\%)$ and $C . Y_{3}$, the tensile strength $\left(\mathrm{kg} / \mathrm{mm}^{2}\right)$

May-June 2019

Indian Journal of Pharmaceutical Sciences
$0.271 \mathrm{~N} / \mathrm{mm}^{2}$, or MPa. The optimised batch of SMMDF showed a tear resistance value of $1.47 \mathrm{~N}$.

The full factorial experimental design required nine runs. The best-fitted model was linear model by Design Expert 10 . The $\mathrm{R}^{2}$, SD and \% CV values are shown in Table 5. The polynomial equation provided by model for the disintegration time is $Y_{1}=26.55556+0.16667$ $\mathrm{X}_{1}+0.50000 \mathrm{X}_{2}$, where $\mathrm{Y}_{1}$ is the disintegration time. All the formulations showed a response of $Y_{1}<30$ s, i.e., 26-27 s. As the amounts of polymer and plasticizer increased, the disintegration time also increased (fig. 3A). The following polynomial equation prevailed from model for drug release, $\mathrm{Y}_{2}=96.59889+0.67833$ $\mathrm{X}_{1}-0.26833 \mathrm{X}_{2}$, where, $\mathrm{Y}_{2}$ was $\%$ drug release. All the formulation showed response of $Y_{2}$ from $95.65 \pm 0.04$ to $98.04 \pm 0.016 \%$. As amount of polymer increased the drug release also increased but as amount of plasticizer increased the drug release decreased (fig. 3B). The polynomial equation for the tensile strength is $\mathrm{Y}_{3}=$ $0.76078+0.15517 \mathrm{X}_{1}+0.067500 \mathrm{X}_{2}$, where, $\mathrm{Y}_{3}$ is the tensile strength. The formulations had $\mathrm{Y}_{3}$ values from 0.55 to $1 \mathrm{~kg} / \mathrm{mm}^{2}$. As the amounts of polymer and plasticizer increased, the tensile strength also increased (fig. 3C).

The optimized batch was FF4 according to Design Expert 10. The percent relative error of the checkpoint batches was between -2.95 and $+2.53 \%$, and it was less than $\pm 10 \%$. The experimental values and predicted values were in good agreement with each other.

The DSC experiments investigated the thermal behaviour of piroxicam and the physical mixture of the SMMDF. The melting peak of piroxicam was observed in the DSC curve of the pure drug at $198.84^{\circ}$. DSC of piroxicam and physical mixture are shown in fig. 4A. DSC measurements made with the drug-loaded physical mixture showed a less sharp endothermic peak compared with the peak of pure piroxicam at $198.84^{\circ}$. The thermogram of the physical mixture showed the endothermic peak of piroxicam although it is broader and shifted slightly to the left, indicating that there is a decrease in the crystalline state. The less sharp endothermic peak indicated that piroxicam might be amorphous in the physical mixture. The presence of similar endothermic peaks in the physical mixture which were associated with the melting point suggested that there was no interaction between the drug and the excipients.

To get further evidence on the change in solid state, $\mathrm{X}$-ray diffraction studies were carried out on the 
untreated drug, the physical mixture with the drug, the physical mixture without the drug and the final formulation as shown in fig. 4B. The diffraction pattern of the final formulation of the SMMDF shows an interesting reduction in the intensity of the peaks. All the peaks are seen, and there are no new diffraction peaks, which rules out any chemical interaction between the components, suggesting that the overall structure of the compound has not changed. This finding is identical to what was found from the DSC and FTIR studies. These findings suggested that the crystal habit of the piroxicam was modified so as to

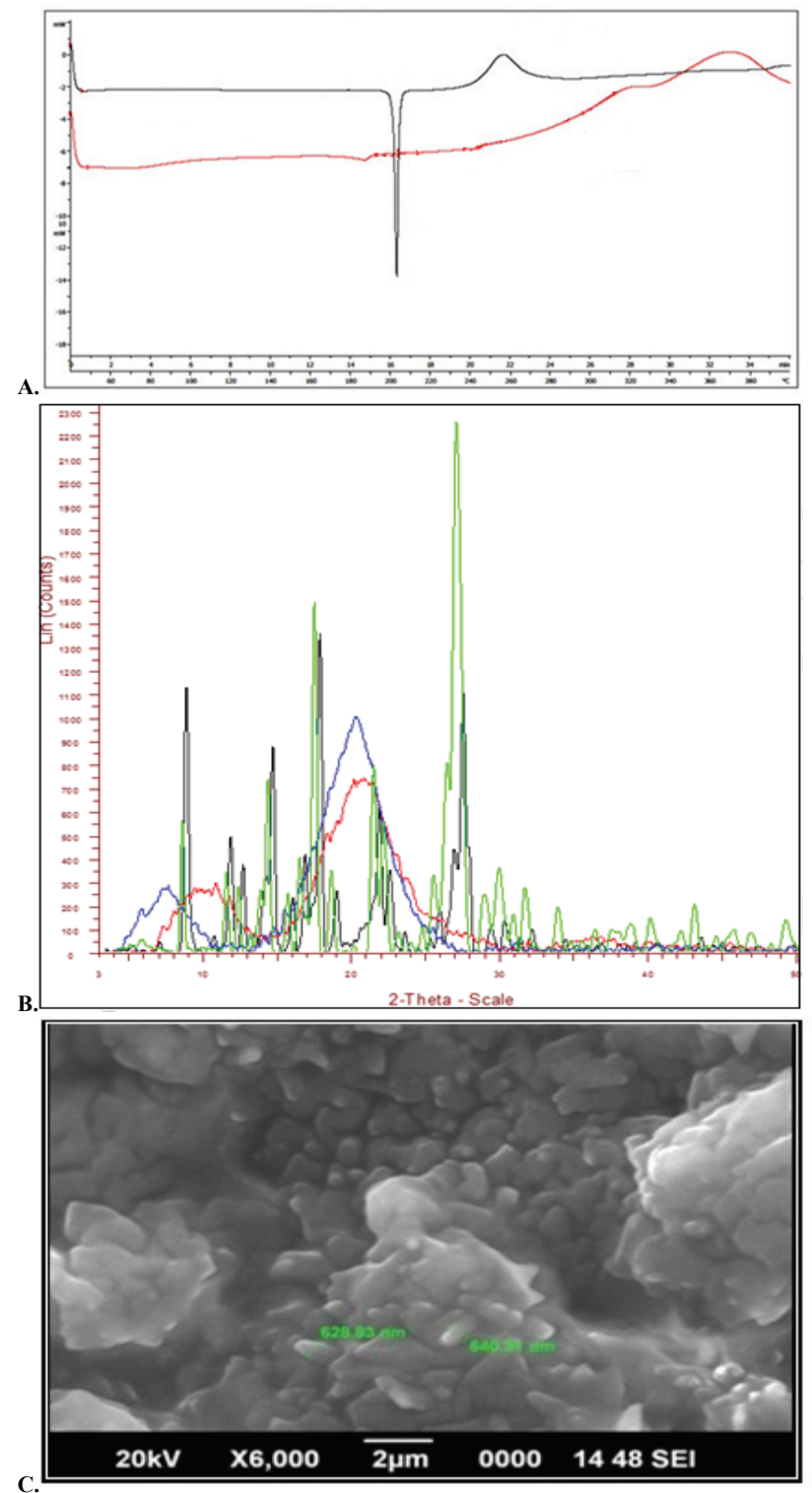

Fig. 4: DSC, X-ray diffraction and SEM studies

A. DSC of piroxicam and physical mixture of self microemulsifying mouth dissolving film, B. (-) physical mixture with piroxicam; (-) physical mixture without piroxicam; (-) final formulation; $(-)$ pure drug piroxicam and $C$. SEM of final formulation of self-microemulsifying mouth dissolving film 
TABLE 6: STABILITY STUDIES FOR OPTIMIZED FORMULATION FF4 OF SMMDF

\begin{tabular}{|c|c|c|c|c|c|}
\hline Time (mo) & Appearance & Weight variation (g) & Disintegration time (s) & Drug content \% & Drug release \% \\
\hline \multicolumn{6}{|c|}{ Long term study at $30 \pm 2^{\circ} / 75 \% \mathrm{RH}_{ \pm} 5 \%$} \\
\hline 0 & Not changed & 0.060 & 26 & 99.87 & 98.04 \\
\hline 3 & Not changed & 0.060 & 25 & 99.87 & 98.00 \\
\hline 6 & Not changed & 0.060 & 26 & 99.87 & 98.00 \\
\hline 9 & Not changed & 0.059 & 25 & 99.85 & 98.00 \\
\hline 12 & Not changed & 0.059 & 26 & 99.85 & 98.00 \\
\hline
\end{tabular}

SMMDF is self-microemulsifying mouth dissolving film

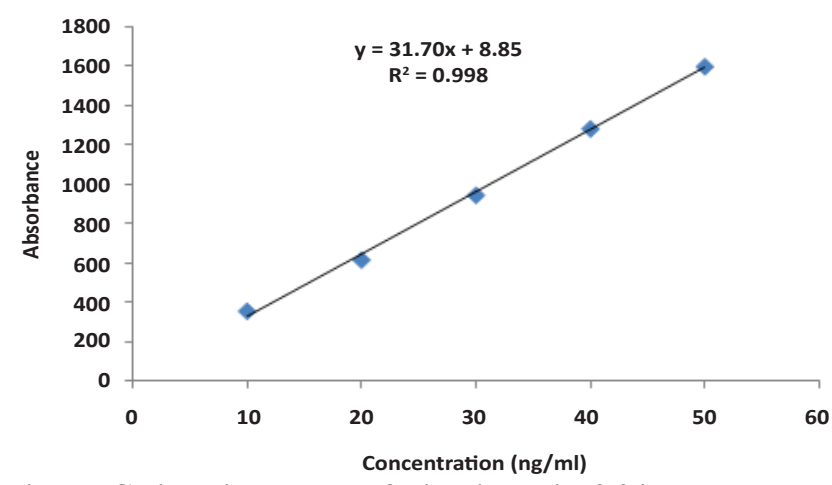

Fig. 5: Calibration curve of piroxicam in $0.04 \mathrm{M}$ phosphate buffer $\mathrm{pH} 8$

TABLE 7: PLASMA DRUG CONCENTRATIONS IN SMMDF AND MARKETED FORMULATION

\begin{tabular}{lcc}
\hline Time $(\mathrm{h})$ & $\begin{array}{c}\text { SMMDF } \\
(\mathrm{ng} / \mathrm{ml})\end{array}$ & $\begin{array}{c}\text { Marketed dispersible tablet } \\
(\mathrm{ng} / \mathrm{ml})\end{array}$ \\
\hline 0.5 & $85.42 \pm 5.2$ & $52.37 \pm 8.4$ \\
1 & $142.63 \pm 7.6$ & $98.15 \pm 7.3$ \\
2 & $426.27 \pm 0.53$ & $172.43 \pm 9.2$ \\
4 & $273.26 \pm 5.9$ & $327.42 \pm 0.46$ \\
6 & $208.72 \pm 8.6$ & $105.64 \pm 6.3$ \\
8 & $132.41 \pm 9.4$ & $91.82 \pm 10.3$ \\
16 & $100 \pm 2.2$ & $80.82 \pm 2.5$ \\
24 & $63.28 \pm 5.9$ & $60.52 \pm 8.6$ \\
\hline Results are expressed as mean \pm SD & $(\mathrm{n}=3), \quad$ SMMDF is self- \\
microemulsifying mouth dissolving film &
\end{tabular}

As observed from comparative evaluation of $\mathrm{t}_{\max }$ of test and reference formulation (Table 8), a statistically significant difference is observed between the rates of drug absorption $(\mathrm{p}<0.05)$. The piroxicam absorption from SMMDF provide a higher $\mathrm{C}_{\text {max }}$ (approximately $13 \%$ higher) with significant difference in $t_{\max }$ $(\mathrm{p}=0.035)$. The $90 \%$ confidence interval of SMMDF and marketed dispersible tablet met the bioequivalence acceptance criteria (90\% confidence interval between 80.00-125.00). The extents of piroxicam absorption $\mathrm{AUC}_{(0-24 \mathrm{~h})}$ and $\mathrm{AUC}_{(0-\infty)}$ from two formulations are comparative and their $90 \%$ confidence intervals are well within the acceptance range of 80.00-125.00. From these pharmacokinetic results it can be concluded that the newly developed SMMDF is bioequivalent both in term of rate $\left(\mathrm{C}_{\max }\right)$ and extent (AUC) of absorption. The prime objective for development of new formulation was to achieve a rapid onset of drug action (low $t_{\max }$ ) without affecting the safety of drug. The outcome of this study provided that newly developed formulation provide a rapid absorption of piroxicam $\left(\mathrm{t}_{\max } \sim 2 \mathrm{~h}\right)$ and is suitable for providing a rapid onset of analgesic action.

Since piroxicam was potent and provide therapeutic effect at low dose $(10 \mathrm{mg})$, it was considered to be an ideal candidate for incorporating into SMMDF. Polymers of SMMDF not only provide desired mechanical properties to the film (shape and strength) but also modulate the release of drug from the formulation. SMMDF were prepared by the solvent casting method on petri plate, using HPMCE15 and L-HPC as polymers. PEG 400 was used as plasticizer and aspartame as sweetener. Distilled water was used as a solvent. Presence of liquid ingredient such as oil, surfactant and co surfactant in formulation presented considerable obstacles in film formation. In order to overcome these drawbacks, Neusilin US2 an oil adsorbing agent was added in the formulation. Neusilin US2 resulted in successful preparation of white film. Modern disintegrating agent such as Polystardone XL crospovidone helped in quick disintegration of the film. HPMC E15 played an important role in the film formation. HPMC E15 helped to enhancing solubility of piroxicam in solvent after co-grinding for $5 \mathrm{~min}$ (in cogrinding method drug and carrier was mixed by using a porcelain mortar and pestle for a specific period). Contact angle reduced since HPMC E15 has surfactant activity, so wetting of drug particles increased and thus dissolution of drug particles improved. Co-grinding method resulted in solubility enhancement of the drug due to the presence of a synthetic polymer. Drug release hindered if high viscosity grades of HPMC were used during drug dissolution. Hence, low viscosity grade polymers such as HPMCE15 was used. Other low viscosity grade polymers such as HPMC E3, HPMC E5 and HPMC E6 were excluded as they exhibited poor film forming ability relative to HPMC E15. The effect 
www.ijpsonline.com

TABLE 8: COMPARATIVE PHARMACOKINETIC PARAMETERS IN RABBITS

\begin{tabular}{lcccc}
\hline $\begin{array}{l}\text { Pharmacokinetic } \\
\text { parameters }\end{array}$ & $\begin{array}{c}\text { SMMDF (test) mean } \pm S D \\
(n=12)\end{array}$ & $\begin{array}{c}\text { Marketed dispersible tablet } \\
\text { (reference) mean } \pm S D(n=12)\end{array}$ & $\begin{array}{c}\% \\
\text { T/R ratio }\end{array}$ & $\begin{array}{c}90 \% \text { confidence } \\
\text { interval }\end{array}$ \\
\hline$C_{\max }(\mathrm{ng} / \mathrm{ml})$ & $426.27 \pm 0.53$ & $375.42 \pm 0.46$ & 113.54 & $104.34-122.74$ \\
$\mathrm{AUC}(0-24 \mathrm{~h}) \mathrm{ng} . \mathrm{h} / \mathrm{ml}$ & $3621.38 \pm 0.14$ & $3358.08 \pm 0.72$ & 107.84 & $101.46-114.34$ \\
$\mathrm{AUC}(0-\infty) \mathrm{ng} . \mathrm{h} / \mathrm{ml}$ & $4489.56 \pm 0.67$ & $4388.35 \pm 0.35$ & 102.30 & $95.63-109.37$ \\
${ }^{*} \mathrm{t}_{\max }(\mathrm{h})$ & $2.0(1.0-3.5)$ & $3.5(1.5-6.0)$ & - & - \\
$\mathrm{Vd}(\mathrm{l})$ & $12.6 \pm 0.43$ & $11.89 \pm 0.27$ & - & - \\
$\mathrm{t} 1 / 2(\mathrm{~h})$ & $8.65 \pm 0.31$ & $9.52 \pm 0.48$ & - & - \\
\hline
\end{tabular}

Comparative pharmacokinetic parameters and comparison of $t_{\max }$ of mouth dissolving tablets, self-microemulsifying mouth dissolving film (SMMDF) and marketed dispersible tablet in rabbits, ${ }^{*} t_{\max }$ provided as median (minima-maxima)

of polymers and plasticizer were studied by preparing various formulations of SMMDF.

Statistical validity of the polynomials was established on the basis of ANOVA provision in the Design Expert software 10. Optimization was performed to find out the level of independent variable $\mathrm{X}_{1}$ and $\mathrm{X}_{2}$. Design Expert software 10 indicated FF4 as optimized formulation.

The SMMDF disintegrated in $26 \mathrm{~s}$, and gave an in vitro drug release of $63.34 \%$ within $60 \mathrm{~s}$ and $98.04 \%$ within 5 min, which confirmed that its self-emulsification performance was preserved. The DSC and X-ray powder diffractometry analyses showed that piroxicam is in an amorphous state within the SMMDF. The outcome of this study was that the newly developed formulation allowed rapid absorption of piroxicam $\left(\mathrm{t}_{\max } \sim 2 \mathrm{~h}\right)$ and appeared to be suitable for providing rapid onset analgesic action. These results further suggested that the SMMDF could be regarded as a novel and commercially feasible approach to introduce into clinical practice.

\section{Acknowledgements:}

The authors thank the Department of Pharmacy, Banasthali University, Rajasthan, India, for providing all facilities to carry out research work.

\section{Conflicts of interest:}

The authors declare that there is no conflict of interest.

\section{Financial support and sponsorship:}

Nil.

\section{REFERENCES}

1. Roger E, Lagarce F, Benoit JP. Development and characterization of a novel lipid nanocapsule formulation of Sn38 for oral administration. Eur J Pharm Biopharm 2011;79:181-8.

2. Xiao L, Yi T, Liu Y. A new self microemulsifying mouth dissolving film to improve the oral bioavailability of poorly water soluble drugs. Drug Dev Ind Pharm 2013;39(9):128490.

3. Shukla P, Prajapati SK, Sharma UK, Shivhare S, Akhtar A. A review on self-micro emulsifying drug delivery system: an approach to enhance the oral bioavailability of poorly water soluble drugs. Int Res J Pharm 2012;3(9):1-6.

4. Chopade VV, Chaudhari PD. Development and evaluation of self-emulsifying drug delivery system for lornoxicam. Int $\mathrm{J}$ Res Dev Pharm Life Sci 2013;2:531-7.

5. Patel MJ, Patel SS, Patel NM, Patel MM. A selfmicroemulsifying drug delivery system (SMEDDS). Int J Pharm Sci Rev Res 2010;4:29-35.

6. Lin SF, Chen YC, Ho HO, Huang WY, Sheu MT, Liu DZ. Development and characterization of dilutable self-micro emulsifying premicroemulsion systems (SMEPMS) as templates for preparation of nanosized particulates. Int $\mathrm{J}$ Nanomedicine 2013;8:3455-66.

7. Rowe RC, Sheskey PJ, Owen SC. Handbook of Pharmaceutical Excipients. 5th ed. London: Pharma Press; 2005. p. 551-72.

8. Verma A, Singh MK, Kumar B. Development and characterization of flutamide containing self-microemulsifying drug delivery system (SMEDDS). Int J Pharm Pharm Sci 2011;3:60-5.

9. Bora D, Borude P, Bhise K. Formulation and Evaluation of Self microemulsifying drug delivery systems of low solubility drug for enhanced solubility and dissolution. Asian J Biomed Pharm Sci 2012;2:7-14.

10. Karki S, Kim H, Na S-J, Shin D, Jo K, Lee J. Thin films as an emerging platform for drug delivery. Asian J Pharm Sci 2016;11:559-74.

11. Mu H, Holm R, Mullertz A. Lipid-based formulations for oral administration of poorly water-soluble drugs. Int J Pharm 2013;453:215-24.

12. Ingle LM, Wankhade VP, Udasi TA, Tapar KK. New Approaches for Development and Characterization of SMEDDS. Int J Pharm Pharm Sci 2013;3:7-14.

13. Ma YJ, Yuan XZ, Peng X, Wang H, Huang H, Bao S, et al. The pseudo-ternary phase diagrams and properties of anionicnonionic mixed surfactant reverse micellar systems. J Mol Liq 2015;203:181-6.

14. Kyatanwar AU, Jadhav AR, Kadam VJ. Self-microemulsifying drug delivery system (SMEDDS): Review. J Pharm Res 2010;3:75-83.

15. Tang J, Sun J, He ZG. Self-emulsifying drug delivery systems: strategy for improving oral delivery of poorly soluble drugs. Curr Drug Ther 2007;2:85-93.

16. Persson LC, Porter CJH, Charman WN, Bergstrom CA. 
Computational prediction of drug solubility in lipid based formulation excipients. Pharm Res 2013;30:3225-37.

17. Thakkar V, Shah A, Gohel M, Baldaniya L, Gandhi T. Optimization of Self Micro Emulsifying Drug Delivery System Containing Curcumin and Artemisinin Using D-Optimal Mixture Design. Saudi J Med Pharm Sci 2017;3(5):388-98.

18. Yeole SE, Pimple SS, Gale GS, Gonarkar AG, Nigde AT, Randhave AK, et al. A Review - Self-Micro Emulsifying Drug Delivery Systems (SMEDDSs). Indo Am J Pharm Res 2013;3:3031-43.

19. Pattewar SV, Kasture SB, Pande VV, Sharma SK. Development and optimization of piroxicam loaded solid self microemulsifying drug delivery system. Indian J Pharm Sci 2018;80(2):350-8.

20. Tomar A, Sharma K, Chauhan NS, Sharma K, Chauhan NS, Mittal A, et al. Formulation and Evaluation of Fast Dissolving Oral Film of Dicyclomine as potential route of Buccal Delivery. Int J Drug Dev Res 2012;4:408-17.

21. Audic JL, Chaufer B. Influence of plasticizers and crosslinking on the properties of biodegradable films made from sodium caseinate. Eur Polym J 2005;41(8):1934-42.

22. Aziz SB. $\mathrm{Li}^{+}$ion conduction mechanism in poly ( $\varepsilon$-caprolactone)-based polymer electrolyte. Iran Polym J 2013;22(12):877-83.

23. Lai F, Franceschini I, Corrias F, Sala MC, Cilurzo F, Sinico $\mathrm{C}$, et al. Maltodextrin fast dissolving films for quercetin nanocrystal delivery: A feasibility study. Carbohydr Polym 2015;121:217-23.

24. Vishwakarma D, Tripathi A, Maddheshiya B. Review article on mouth dissolving film. J Global Pharm Technol 2011;3:1-8.

25. Patil A, Ghorwade V, Patil S, Ikkurthi K, Inuganti KS, Porandla V. Formulation and evaluation of Montelukast sodium fast dissolving films by using Gelatin as a film base. Res J Pharm Biol Chem Sci 2011;3:880-8.

26. Rajesh M, Ravikiran N, Palanichamy S, Rajadhas TG, Anusha V, Parasakthi N, et al. Formulation and Evaluation of Orodispersible Piroxicam Tablets. J Pharm Sci Res 2010;2:615-21.

27. Liew KB, FungTan YT, Peh KK. Characterization of Oral Disintegrating Film Containing Donepezil for Alzheimer Disease. AAPS Pharm SciTech 2012;13:134-42.

28. Patil P, Shrivastava SK. Fast Dissolving Oral Films: An Innovative Drug Delivery System. Int J Sci Res 2014;3:208893.

29. Bahrami SB, Kordestani SS, Mirzadeh H, Mansoori P. Poly (vinyl alcohol)-chitosan blends: preparation, mechanical and physical properties. Iran Polym J 2003;12(2):139-46.

30. El-Setouhy DA, El-Malak NSA. Formulation of a Novel Tianeptine Sodium Orodispersible Film. AAPS PharmSciTech 2010;11:1018-25.

31. Brahmankar DM, Jaiswal SB. Biopharmaceutics and pharmacokinetics- A Treatise. 3rd ed. Delhi: Vallabh Prakashan; 2015. p. 237-57.

32. Rajab NA, Jawad MS. Formulation and in vitro evaluation of piroxicam microsponge as a tablet. Int J Pharm Pharm Sci 2015;8(2):104-14.

33. Silverstein RM, Webster FX. Spectrometric identification of organic compounds. 6th ed. India: Wiley; 2010. p. 87-102.

34. Pattewar SV. Solubility enhancement of poorly aqueous soluble drug-simvastatin by using HPMCE3LV. Int J Pharm Pharm Sci 2012;4:498-502.

35. Patel D, Patel M, Upadhyay P, Shah N, Shah S. A Review on Mouth Dissolving Film. J Pharm Sci Biosci Res 2015;5(3):266-273.

36. Zein EE, Gizawy SE, Kayad SE. Preparation, characterization and in vitro evaluation of piroxicam microspheres. Eur J Pharm Med Res 2016;3:99-105.

37. Bhargav E, Reddy CSP, Sowmya C, Haranath C, Khan KAA, Rajesh $\mathrm{K}$, et al. Formulation and optimization of piroxicam orodispersible Tablets by Central Composite Design. J Young Pharm 2017;9(2):187-91. 